
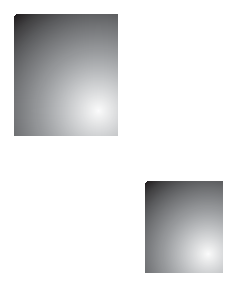

\section{A Normalidade do Business no Ensino da Administração e a Marginalização do Público e do Social}

The Business of Addiction in Management Education and the Public and Social Marginalization

Marcos Adller de Almeida Nascimento

Universidade Federal do Rio Grande do Norte. Professor do Departamento de Ciências Sociais e Humanas. Currais Novos. Rio Grande do Norte. Brasil. E-mail: adller_almeida@yahoo.com.br

Maria Arlete Duarte de Araújo

Universidade Federal do Rio Grande do Norte. Professora Titular do Departamento de Ciências Administrativas. Natal. Rio Grande do Norte. Brasil. E-mail: mariaarlete@gmail.com

\section{Resumo}

A hipótese norteadora deste percurso investigativo é a de que Cursos de Administração em universidades públicas brasileiras apresentam matrizes curriculares que privilegiam o espaço privado e a economia de mercado em detrimento dos temas da Administração Pública (AP) e do ambiente de sua congênere, a Gestão Social (GS). O objetivo do artigo é, então, compreender o espaço que o ensino de conteúdos da administração pública ocupa em cursos de administração "generalistas". Em linhas gerais, os resultados alcançados corroboram com a hipótese de que a disciplina de Administração Pública é pouco explorada em processos generalistas de ensino-aprendizagem na graduação de administração.

Palavras-chave: Administração Pública. Ensino de Administração. Mercadocentrismo.

\section{Abstract}

The guiding hypothesis of this researching is that Administration courses in Brazilian public universities have curriculum matrices that favor the private space and the market economy to the detriment of the themes of the Public Administration and the environment of its counterpart, the Social Management. The aim of the paper is then to understand the space that the government teaching content occupies in "general" management courses. In general, the results obtained corroborate the hypothesis that the discipline of Public Administration is little explored in teaching-learning processes in general management degree.

Keywords: Public Administration. Management Education. Market Hegemony. 


\section{INTRODUÇÃo}

A Resolução n 4/2005 do Conselho Nacional de Educação, ao instituir as novas Diretrizes Curriculares Nacionais (DCN) para os Cursos de Administração, na modalidade Bacharelado, dispõe - em seus terceiros parágrafos do artigo $2^{\circ}$ e artigo $3^{\circ}$ - a respeito da pluralidade de campos de atuação a ser observada no processo de formação de administradores. No artigo $2^{\circ}$, a Resolução estabelece que as linhas de formação específica nas diversas áreas da Administração não devem ser empregadas na formatação de cursos com habilitações particulares. Nesse sentido, as Diretrizes Curriculares vigentes para os cursos de Administração sustentam o viés generalista da formação de administradores. $\mathrm{O}$ artigo $3^{\circ}$ é ainda mais incisivo no que toca à necessidade de reserva do aspecto multiorganizacional no âmbito do ensino superior em Administração quando afirma:

O Curso de Graduação em Administração deve ensejar, como perfil desejado do formando, capacitação e aptidão para compreender as questões científicas, técnicas, sociais e econômicas da produção e de seu gerenciamento, observados níveis graduais do processo de tomada de decisão, bem como para desenvolver gerenciamento qualitativo e adequado, revelando a assimilação de novas informações $e$ apresentando flexibilidade intelectual e adaptabilidade contextualizada no trato de situações diversas, presentes ou emergentes, nos vários segmentos do campo de atuação do administrador. (ANGRAD, 2005, p. 2, grifo nosso)

O que se entende a partir da expressão "[...] vários segmentos do campo de atuação do administrador"? A Resolução n. 4/2005, neste recorte do artigo $3^{\circ}$, faz menção à divisão tradicional, ou seja, às áreas funcionais a partir das quais a Administração é operacionalizada (marketing, finanças, produção, recursos humanos etc.)? É factível ampliar essa compreensão, restritiva da multidisciplinaridade da atuação do administrador à dimensão funcional, ao nível da diversidade relativa à natureza das organizações nas quais o administrador pode atuar?

Considera-se, portanto, que a prevalência do viés hegemônico do paradigma de mercado se constitui componente redutor da complexidade inerente à dinâmica interorganizacional a que deve responder o processo de formação do administrador, independentemente da raiz epistemológica a qual se vincule o projeto político pedagógico dos cursos. Lopes (2006, p. 5), critica o aspecto restritivo ao qual se submete o argumento de que o exercício profissional do administrador se dá em contextos organizacionais intransigentes e atrelados a processos decisórios pré-definidos.

O exercício profissional da Administração ocorre num contexto novo de grande dinamismo econômico e de rápidas mudanças no ambiente dos negócios, de modo que se definem exigências mais amplas que a simples utilização de um arsenal de técnicas gerenciais, subdividido em áreas específicas da organização, aplicáveis em contextos decisórios pré-definidos.

Assim, considera-se essencial à consecução do objetivo de formação integral do administrador a manutenção ou a inclusão de estratégias e conteúdos formativos que lancem luz sobre as interfaces próprias das relações interorganizacionais, de modo que sejam evidenciadas as recíprocas dependências que transpassam os setores público, privado e social.

Neste artigo, essa discussão encontra refúgio e se assenta sobre a ideia de que os Cursos de Graduação em Administração devem viabilizar uma experiência democrática de conhecimento no universo organizacional.

A hipótese norteadora deste percurso investigativo é a de que cursos de Administração em universidades públicas brasileiras apresentam matrizes curriculares que privilegiam o espaço privado e a economia de mercado em detrimento dos temas da Administração Pública (AP) e do ambiente de sua congênere, a Gestão Social (GS). A cobertura de conteúdos obrigatórios voltados às discussões sobre a Administração Pública e a Gestão Social em currículos de Cursos de Graduação em Administração é, pois, o foco da análise sustentada por esta pesquisa.

Coelho (2006), em sua tese de doutoramento, produziu análises acerca do desenvolvimento do ensino superior no campo da Administração Pública. A temática de estudo do professor Fernando Coelho trata, no entanto, da evolução e panorama do ensino de Administração Pública por meio de estruturas curriculares dedicadas, particulares. Este artigo reveste-se de outro sentido na medida em que objetiva discutir o espaço que o ensino da Administração Pública e da 
Gestão Social têm tido nas estruturas curriculares dos Cursos de Graduação em Administração, de formato generalista. Interpõem-se como limitações principais a esta investigação: a) o quantitativo de currículos analisados; $e$ b) a superficialidade da análise dada a impossibilidade de acesso aos Projetos Políticos Pedagógicos dos cursos pesquisados.

Do ponto de vista teórico, os argumentos em defesa de uma visão econômico-organizacional plural, aportados neste artigo, foram capturados nas obras de Polanyi (1944) e Ramos (1989). A condição do atual dimensionamento das grades curriculares de Cursos de Administração em universidades públicas com centros de referência em estudos organizacionais é discutida à luz dos conceitos de paradigma e revolução científica constantes em Kuhn (1978). No texto, ainda são dispostas colaborações de alguns autores (COELHO, 2006; FRANÇA FILHO, 2004; CANÇADO, 2011) que se preocupam com a delimitação dos espaços distintos que ocupam a Gestão Empresarial e a Administração Pública e a Gestão Social.

O artigo está dividido em cinco tópicos. O primeiro reserva-se à exposição das posturas epistemológicas sustentadoras da pesquisa. O tópico subsequente apresenta o framework teórico do estudo. Na terceira parte discutem-se as opções metodológicas adotadas e, por fim, nos quarto e quinto tópicos são apresentadas a análise dos resultados e as considerações finais.

\section{As Organizações e a Economia além do Mercado}

Nos domínios do ensino e da pesquisa em Administração permanece atual a disputa - em âmbito teórico e também ideológico - entre as perspectivas gerenciais, instrumental e substantiva. Protagonizando este embate epistemológico dispõem-se, do modo antagônico, a lógica de mercado, baseada na maximização dos interesses individuais, e a lógica da solidariedade, baseada na isonomia, na autonomia $e$ no desenvolvimento comunitário.

No livro A Nova Ciência das Organizações (1989), Alberto Guerreiro Ramos tece um conjunto de críticas ao centralismo do instituto "mercado" na (re)produção da vida em sociedades contemporâneas. Este mesmo autor propõe um modelo multidimensional para a análise e compreensão de sistemas sociais, um novo paradigma em oposição ao enfoque centrado no mercado.

O paradigma para-econômico advoga uma sociedade suficientemente diversificada para permitir que seus membros cuidem de tópicos substantivos de vida, na conformidade de seus respectivos critérios intrínsecos, e no contexto dos cenários específicos a que esses tópicos pertencem. [...] a para-economia pode ser entendida também como proporcionadora da estrutura de uma teoria política substantiva de alocação de recursos e de relacionamentos funcionais entre enclaves sociais, necessários à estimulação qualitativa da vida social dos cidadãos. (RAMOS, 1989, p. 177-178)

Souza e Oliveira (2006) retomam discussão de Chevallier e Lorschak (1980) inerente aos problemas epistemológicos que acometem a definição de um campo científico para a Administração. Segundo Chevallier e Lorschak (1980 apud SOUZA; OLIVEIRA, 2006), a constituição da Ciência Administrativa é marcada por dois estilos: o compósito, referente à heterogeneidade característica às contribuições teóricas oriundas de diferentes campos do conhecimento (psicologia, engenharia, economia, ciência social etc.) e, portanto, com reduzido potencial coesivo (a Administração como uma colcha de retalhos, formada a partir de tecidos teóricos distintos); e o compartimentado, relativo ao intuito limitado, pela diversidade de contextos sob os quais as correntes de estudos organizacionais se desenvolveram, para estabelecer um trajeto histórico-conceitual, para uma suposta Ciência Organizacional, sustentado por uma cronologia e uma espacialidade suficientemente demarcadas.

Ramos (1989) soma aos estilos dispostos por Chevallier e Lorschak (1980) duas outras falhas epistemológicas presentes no processo de construção da Ciência Administrativa: o americanismo, dado o relativo monopólio dos construtos organizacionais - na produção científica, nos projetos de ensino - produzidos em contextos norte-americanos, e o reducionismo mercadológico, traduzido como a parcialidade da análise organizacional, pautada num business management, ante a pluralidade de outros formatos organizacionais em interação com as variadas facetas da experiência humana. 
Polanyi (2000), ao discutir substantivamente o significado do termo economia, oferece outra plataforma teórica para o enfraquecimento da ideia de espontaneidade no processo de desenvolvimento duma sociedade centrada no mercado. Segundo o autor, o advento de um sistema econômico - baseado no princípio da maximização do interesse individual - separado da produção social humana precisa ser compreendido como evento recente e inédito no decurso da história da humanidade. Polanyi (2000, p. 69), ao caracterizar parte das relações comerciais comuns à sociedade em período que antecede a era da Revolução Industrial (em meados do século XVIII), elucida que (naquele contexto):

[...] é vedada a ideia do lucro; as disputas e os regateios são desacreditados; o dar graciosamente é considerado como virtude; não aparece a suposta propensão à barganha, à permuta $e$ à troca. Na verdade, o sistema econômico é mera função da organização social.

Nessa perspectiva, partindo de uma proposta de ressignificação epistemológica do instituto "economia”, Polanyi (2000) defende a pluralidade de dimensões econômicas, em superação ao mimetismo mercadológico, suportadas em outros três princípios de comportamento econômico: o da redistribuição, o da reciprocidade e o da domesticidade. Serva (1997, p. 19), explica que "Polanyi rejeitava a ideia de que a razão instrumental tem que ser empregada como o ponto de partida para a análise de toda e qualquer atividade econômica". Na interpretação desse autor, Polanyi se posiciona contrário à supressão que o centralismo da racionalidade instrumental e da dimensão do mercado condiciona o conjunto das relações econômicas substantivas.

Ramos (1989) e Polanyi (2000) estabelecem, então, uma plataforma epistemológica que advoga em favor do desenvolvimento da análise organizacional e da análise econômica atentas à diversidade das relações sociais e à multidimensionalidade das trocas produzidas no seio das sociedades, ao longo dos anos $e$ em diferentes contextos territoriais e culturais. Fundamentalmente, a construção deste artigo se dá à luz do corpo teórico desenvolvido por Guerreiro Ramos e por Karl Polanyi.

A Administração Pública (AP), a Administração Empresarial (AE) e a Gestão Social configuram, portan- to, o conjunto das opções epistemológicas disponíveis para a caracterização dos programas de ensino na área de gestão. Cada uma destas opções, por seu turno, não olvidado o aspecto da intersetorialidade própria à dinâmica de funcionamento das organizações, pode ser representado por um tipo organizacional específico, com natureza distinta dos demais. Andion (1998) atrelou a análise da taxonomia organizacional aos denominados "tipos de economia". Nessa seara, as empresas privadas, objetos da Administração Empresarial, constituem o grupo das organizações da economia formal. Estas organizações, cujo objetivo principal é a remuneração do capital mediante a produção e oferta de bens e serviços em atenção às demandas e desejos dos clientes, operam sob o compasso do princípio de comportamento econômico do mercado - defino por Polanyi (2000) - e iluminadas, predominantemente, pela lógica constitutiva de uma racionalidade instrumental (RAMOS, 1989).

De acordo com Andion (1998), as organizações vinculadas à economia social ou à economia solidária compõem universo organizacional de interesse da Gestão Social. Cooperativas, associações, organizações comunitárias, organizações de assistência e entidades representativas exemplificam tipologias organizacionais enlaçadas à Gestão Social. Por objetivo principal, têm o desenvolvimento emancipado de indivíduos e de coletividades. Nesse tipo de organização predominam a racionalidade substantiva (RAMOS, 1989) e os princípios de comportamento econômico da reciprocidade e da domesticidade (POLANYI, 2000). Sua origem está atrelada à articulação autônoma de pessoas e/ou comunidades em torno de interesses coletivos.

Cançado (2011) indica que o campo da Gestão Social se constitui em empreendimento cujo desenvolvimento se encontra em estágio inicial, carente de contribuições teóricas que colaborem com o processo de delimitação do seu espaço. Cançado, Pereira e Tenório (2013) consideram antagônicos os modos de gerir de que lançam mão a Gestão Social e a Gestão Empresarial. Em esforço pela delimitação de um conceito, os autores indicam que

[...] a Gestão Social é a tomada de decisão coletiva, sem coerção, baseada na inteligibilidade da linguagem, na dialogicidade e no entendimento esclarecido como processo, na transparência como pressuposto e na emancipação enquanto fim último. (CANÇADO; PEREIRA; TENÓRIO, 2013, p. 132) 
A Gestão Social e Administração Pública compartilham o mesmo espaço quando observado o escopo das ações de suas organizações: a esfera pública. A Gestão Social importa que as pessoas privadas se apropriem dos espaços públicos e passem exercer o controle social sobre as políticas e ações governamentais. O objeto da Administração Pública, todavia, constitui-se da gestão dos interesses do Estado. As organizações públicas também podem ser associadas aos princípios de comportamento econômico desenhados por Polanyi (2000). Nesse caso, o princípio da redistribuição, haja vista o modelo de financiamento da ação governamental - via arrecadação de impostos, contribui para a particularização e caracterização da função a que se destina a máquina pública.

\section{A Normalidade do Business no Ensino da Administração e a Marginalização do Público e do Social}

A discussão empreendida neste artigo reconhece a jovialidade do fenômeno do ensino em Administração no Brasil. Estudo desenvolvido por Teixeira et al. (2011) ilustra que somente na década de 1950, a partir da criação da Escola de Administração Pública (EBAP) e da Escola de Administração de Empresas de São Paulo (EAESP), ambas pela Fundação Getúlio Vargas, inauguraram-se as primeiras estruturas de ensino especializadas em administração no Brasil. As escolas americanas do public administration e do business managment foram as principais referências neste processo de organização do ensino em administração no Brasil. Com a insurgência e hegemonização do modelo de desenvolvimento neoliberal norte-americano - no ocidente e na segunda metade do século $\mathrm{XX}$ - em detrimento do fortalecimento da figura dos Estados como promotores e coordenadores das liberdades individuais e do desenvolvimento coletivo, à administração pública passa a ser atribuído, indistintamente, o rótulo de modelo de gestão ineficaz (BRESSER-PEREIRA, 2009).

No que se refere aos efeitos desse macromovimento econômico-social sobre os rumos seguidos pelo ensino de administração no Brasil, observa-se sobretudo nas duas últimas décadas do século XX - a extenuação por que passaram os conteúdos dedicados ao ensino da administração pública nas estruturas curriculares específicas ou compartilhadas. Coelho e Nicolini (2013) enriquecem a explicação deste processo de extenuação a que se submeteu o ensino de Administração Pública no Brasil apontando outras particularidades inerentes aos contextos organizacional, econômico e político, brasileiros no pós-década de 1970. A pesquisa dos autores elencou um conjunto de condições favoráveis a esta retração:

O estadocentrismo (tecnocrático e antidemocrático) ocultou e tolheu a especificidade da AP como área de ensino e pesquisa no país. [...] $\mathrm{Na}$ realidade, a aderência entre análise econômica $e$ planejamento governamental - estendido às políticas públicas - e o vínculo entre gestão e empresa pública, projetava os bacharelados em economia e AE como cursos apropriados para a estrutura administrativa do Estado autoritário e indicados para a conjuntura econômica e empresarial nacional. [...] A junção do ensino superior de AP e AE pelo currículo mínimo, corroborada pelo Estado-empresa, pelo milagre econômico e, em termos, pelo desfavorável mercado de trabalho para o administrador público à época, além de resultar em falhas e lacunas na formação acadêmica em AP, atrofiou, ligeiramente, o seu ensino no país. (COELHO; NICOLINI, 2013, p. 13)

Destarte, esses autores aventam a vigência de uma nova fase no desenvolvimento do ensino em Administração no Brasil. Esta nova fase se caracteriza pelo fortalecimento de um movimento articulado na direção da delimitação do denominado "Campo de Públicas". Como consequência deste processo despontam demandas pela criação e fomento de espaços próprios para a discussão dos temas da Gestão Pública nas instituições de ensino superior, evidenciando a tendência da separação entre os campos público e privado nos projetos pedagógicos dos cursos de administração no Brasil.

A hipótese que aglutina e motiva os esforços investigativos neste estudo - a reboque da discussão levanta até aqui - preconiza a existência de normalidade dentro do contexto do ensino de Administração, em nível superior, no Brasil. Essa normalidade, a priori hipotética, refere-se ao reducionismo epistemológico ao qual está condicionado o ensino da Administração, tendo em vista a hegemonia do viés mercadológico ante o dimensionamento da carga horária obrigatória em currículos de Cursos de Graduação em Administração. 
O conceito de comunidade científica discutido em Kuhn (1978) é creditado, neste estudo, como a vertente em que se apoia a explicação, parcializada, do positivismo associado ao ensino em Administração. As comunidades científicas constituem-se, pois, como grupos de indivíduos afiliados pela compatibilidade dos seus interesses inerentes ao processo de construção do conhecimento. De uma forma geral, as contribuições que as comunidades científicas emprestam ao processo de construção do conhecimento são reproduções de textos matriciais (literaturas-padrão) que lançam mão de uma visão unívoca sobre um mesmo objeto de estudo, ainda que em contextos e épocas distintos (KUHN, 1978; RAMOS, 1989).

No campo dos estudos organizacionais, do ponto de vista histórico, essas comunidades são representadas pelas escolas do pensamento em Administração, a exemplo da Escola das Relações Humanas, do Estruturalismo, do Contingencialismo entre outros (MOTTA; VASCONCELOS, 2006). O campo do conhecimento por onde transitam os estudos organizacionais, segundo Aktouf (2004), é marcado pelo predomínio da literatura norte-americana $e$, consoante a esse aspecto, pelo viés exclusivista do mercado como mediador das relações sociais:

Como aceitar que gerações inteiras de estudantes de administração sejam - em geral ensinadas a pensar de acordo com o sistema elaborado por Porter, sem espírito crítico ou outras referências? (AKTOUF, 2004, p. 96)

[...] escreve-se ou diz-se sistematicamente "administração", sem outras especificações, quando se trata da administração à americana, e "administração à moda japonesa", "alemã", "sueca" etc., fazendo passar automaticamente essas "outras" administrações por administrações específicas, carregadas de especificidades culturais, e mesmo de extravagâncias, de modo que seria impossível imitá-las, estendê-las a outros países. (AKTOUF, 2004, p. 128)

O porteirismo e a americanização operam, então, como processos limitadores da compreensão do universalismo por trás da administração como campo disciplinar. Aktouf (2005) contesta o privilégio com que os conteúdos de natureza técnica são associados ao percurso de formação em administração. Em contraposição, o autor argumenta em defesa de uma educação gerencial pautada sob o interesse social, sob uma visão coletiva e potencialmente redutora das desigualdades sociais.
Fischer (1984), ao discutir sobre a natureza da Administração Pública, apresenta dois caminhos possíveis para o enquadramento epistemológico do tema. De acordo com a autora, a aceitação da Administração como uma disciplina em particular é minada tanto pela heterogeneidade das contribuições teóricas que a constituem, quanto pela permeabilidade com os problemas do mundo real que o praticismo lhe confere. A proposta que segue, então, é a de conceituar a Administração como uma interdisciplina ou como uma área do conhecimento em interseção.

Numa outra linha de argumentação, Fadul (2009) sustenta o caráter disciplinar da Administração ao tempo em que apresenta quatro modalidades a partir das quais podem ser interpretados conhecimentos $e$ práticas administrativas: a administração, além de sua condição como disciplina científica e disciplina acadêmica - nascida ao final do século XIX -, não menosprezados todos os flancos epistemológicos que as afetam (CHEVARLIER; LORSCHAK, 1980; RAMOS, 1989; AKTOUF, 2004; BERTERO, 2006), é integrada, ainda, pelos vieses disciplinares tecnológico e profissional.

Noutro desdobramento atrelado à evolução no processo de escolarização da "Administração" ao longo do século XX, estão dispostas em campos distintos a disciplina dos estudos organizacionais - despontando como que um redimensionamento da disciplina da Administração Empresarial - e a disciplina da Administração Pública. Reforçando a crítica à disseminação indiscriminada do ensino da gestão made in USA produzida por Aktouf (2004), Bertero (2006 apud FADUL, 2009) coloca que o processo de escolarização da Administração no Brasil sofreu forte influência norte-americana. A disciplina da Administração Pública, no decurso desta evolução didático-teórica, mesmo tendo vivido - sobretudo nas duas últimas décadas do último milênio - anos de descrédito e negligência quanto a sua relevância, no final do século XX é ressignificada e retoma sua importância em espaços acadêmicos a partir das transformações referentes ao papel do Estado (COELHO, 2006; FADUL, 2009).

Coelho (2006) explica que esse novo fôlego, alusivo ao reposicionamento da disciplina da Administração Pública - agora concebida como estratégia para a manutenção do desenvolvimento do país -, tem se refletido no Brasil adentro na criação de Cursos de Graduação em Administração vocacionados especificamente à esfera pública. "[...] foi no decorrer da segunda metade dos anos noventa, na esteira das 
transformações da administração pública brasileira, que o ensino de graduação nessa campo do saber voltou a ser cogitado no país" (COELHO, 2006, p. 98).

Um resultado inerente a este movimento recente foi o estabelecimento, no ano de 2014, das Diretrizes Curriculares Nacionais para os Cursos de Graduação em Administração Pública. Antes disso, no ano de 2005, a partir da vigência da Resolução n. 04/2005 do Conselho Nacional de Educação, um cenário para o desenvolvimento do ensino em nível superior de Administração passou a ser construído. A Resolução n. 04/2005/CNE/CSE/MEC é responsável - dentro do conjunto das Diretrizes Nacionais para Cursos Bacharelados de Administração - pela extinção das habilitações, outrora extensivamente utilizadas para qualificar tipos específicos de administradores. Quase 250 tipos de habilitações haviam sido criados com o intuito de distinguir vieses particulares na formação de bacharéis em Administração (COELHO, 2006).

Como implicação direta desta Resolução, desde o ano de 2007, os cursos de Graduação em Administração voltados à formação de bacharéis que compreendem a dinâmica do setor público tornaram-se

[...] obrigatoriamente, ou um bacharelado em administração pública, ou uma linha de formação específica do bacharelado em administração; no primeiro caso, adotar-se-á a denominação "curso de administração pública" e, no segundo caso, a linha de formação específica em administração pública, constante do projeto pedagógico do curso, não poderá ser uma extensão (ou apêndice) de sua nomenclatura, mantendo-se - exclusivamente - o nome de "curso de administração”. (COELHO, 2006, p. 95)

Nos últimos vinte anos, o quantitativo de Cursos de Administração Pública foi significativamente redimensionado. Em pesquisa realizada por Coelho (2006), consta que até ano de 2006, existiam no país, setenta e oito cursos de natureza similar. Nesse bojo estão todos os cursos ofertados por instituições de ensino privadas, públicas e do terceiro setor. Na atualidade, conforme dados do e-MEC (2013), existem no Brasil, setenta e quatro cursos presenciais de graduação, nas modalidades bacharelado ou tecnólogo, gratuitos, que em sua denominação carregam as expressões "administração pública" ou "gestão pública" ou "políticas públicas". Se atendidos estes mesmos critérios (curso de graduação, presencial, gratuito, bacharelado ou tecnológico), restringindo-se a busca ao total de cursos denomina- dos exatamente através da expressão "administração pública", encontram-se 17 cursos. Excluem-se dessa contagem os cursos ofertados à distância e os presenciais de instituições que cobram mensalidade.

A pesquisa de que trata este artigo visa compreender o espaço que o ensino de conteúdos próprios da administração pública ocupa em cursos de administração à moda generalista.

\section{Procedimentos Metodológicos}

Este estudo tem natureza qualitativa. A web se constitui como fonte exclusiva dos dados interpretados no processo analítico desta investigação. As grades curriculares dos Cursos de Administração das dez instituições de ensino que compõem esta pesquisa bem como as ementas de disciplinas específicas foram acessadas através do uso da internet, via sites oficiais dos cursos em cada uma das universidades envolvidas. Algumas ementas foram consultadas, dada a necessidade de confirmação da vinculação de componentes ao campo de administração pública, tendo em vista a apresentação inicial de nomenclatura não conclusiva frente ao interesse desta pesquisa. Os critérios de delimitação do estudo serão expostos na sequência do texto de maneira detalhada.

Os critérios de delimitação da abrangência do estudo observam dois pontos em particular: a) buscou-se filtrar, inicialmente, as estruturas de Cursos de Graduação em Administração lotados em instituições de ensino superior (IES) com qualificada inserção no campo de estudos organizacionais. Para tanto, compuseram uma lista preliminar, as IES que aportavam programas de Pós-Graduação em Administração com avaliação, pela Coordenação de Aperfeiçoamento de Pessoal de Nível Superior (CAPES), igual ou superior a cinco, recortados os dados das avaliações nos dois últimos triênios (2007-2009 e 2010-2012).

Considera-se que esse grupo seleto de Programas de Pós-Graduação em Administração lidera o processo de desenvolvimento da ciência no âmbito dos estudos organizacionais e dele, dentro de uma visão "kuhniana", remontando o papel das comunidades científicas, emanam as tendências que orientam a pesquisa e o ensino em administração no contexto nacional, tendo em vista a função de formação de novos professores/ pesquisadores exercida por esses programas; b) Depois de identificados os Cursos de Graduação compatíveis 
com o critério de partida, optou-se por restringir a análise ao contexto das universidades públicas. Essa escolha está atrelada à necessidade de redução do volume de informações disponíveis para a análise e a tentativa de comparação de estruturas curriculares de cursos oriundos de instituições de ensino com a mesma natureza, qual seja, pública.

Trata-se, então, de um estudo de múltiplos casos, selecionados a partir de um processo amostral (apriorístico) voltado "[...] para o preenchimento dos campos [atendimento aos critérios de inclusão, incluído pelo autor] da estrutura da forma mais uniforme possível" (FLICK, 2009, p. 118). A pesquisa caracteriza-se por sua finalidade exploratório-descritiva.

Dez cursos de graduação em administração atenderam simultaneamente aos dois critérios de delimitação da abrangência da pesquisa, são eles:

\begin{tabular}{|c|c|c|c|}
\hline IES & $\begin{array}{l}\text { Programa de } \\
\text { Pós-Gradua- } \\
\text { Ção EM Adm. }\end{array}$ & $\begin{array}{c}\text { AvaliaÇão } \\
\text { CAPES } \\
2007- \\
2009\end{array}$ & $\begin{array}{c}\text { AvaliaÇão } \\
\text { CAPES } \\
2010- \\
2012\end{array}$ \\
\hline $\begin{array}{l}\text { Universidade de } \\
\text { São Paulo - USP }\end{array}$ & PPGA/USP & 7 & 7 \\
\hline $\begin{array}{c}\text { Universidade } \\
\text { Federal de Minas } \\
\text { Gerais - UFMG }\end{array}$ & $\begin{array}{l}\text { CEPEAD/ } \\
\text { UFMG }\end{array}$ & 6 & 6 \\
\hline $\begin{array}{l}\text { Universidade Federal } \\
\text { da Bahia - UFBA }\end{array}$ & NPGA & 5 & 5 \\
\hline $\begin{array}{l}\text { Universidade de } \\
\text { Brasília - UnB }\end{array}$ & PPGA/UnB & 5 & 5 \\
\hline $\begin{array}{l}\text { Universidade Federal } \\
\text { do Rio Grande do } \\
\text { Sul - UFRGS }\end{array}$ & $\begin{array}{l}\text { PPGA/ } \\
\text { UFRGS }\end{array}$ & 7 & 5 \\
\hline $\begin{array}{l}\text { Universidade Federal } \\
\text { de Lavras - UFLA }\end{array}$ & PPGA/UFLA & 4 & 5 \\
\hline $\begin{array}{l}\text { Universidade Federal } \\
\text { do Rio Grande do } \\
\text { Norte - UFRN }\end{array}$ & PPGA/UFRN & 4 & 5 \\
\hline $\begin{array}{l}\text { Universidade Federal } \\
\text { da Paraíba - UFPB }\end{array}$ & PPGA/UFPB & 4 & 5 \\
\hline $\begin{array}{l}\text { Universidade Federal } \\
\text { de Pernambuco } \\
\text { - UFPE }\end{array}$ & $\begin{array}{l}\text { PROPAD/ } \\
\text { UFPE }\end{array}$ & 5 & 4 \\
\hline $\begin{array}{l}\text { Universidade } \\
\text { Federal do Rio de } \\
\text { Janeiro - UFRJ }\end{array}$ & $\begin{array}{l}\text { COPPEAD/ } \\
\text { UFRJ }\end{array}$ & 5 & 4 \\
\hline
\end{tabular}

Quadro 1: Instituições que atenderam aos critérios de delimitação da pesquisa

Fonte: Elaborado pelos autores deste artigo
As matrizes curriculares observadas, em todos os casos, pertencem a cursos de Graduação em Administração (bacharelado) ofertados presencialmente. Outras graduações na área de gestão ou no campo das ciências organizacionais, direcionadas à formação - além de bacharéis - de tecnólogos, foram identificados no conjunto de cursos com oferta de vagas no que concerne ao grupo de universidades atreladas a esta pesquisa. Todavia, dentro do esforço por tornar aceitável o viés comparativo do estudo, optou-se pela inclusão de cursos cuja nomenclatura se restringisse ao identificador "administração" e, ao mesmo tempo, vocacionados à formação de bacharéis.

A busca pelos currículos, de uma forma geral, não implicou em problema ao processo de coleta de dados: os links dos cursos, bem como os de suas respectivas estruturas curriculares, foram facilmente identificados e acessados. A Pesquisa Qualitativa Online, segundo Flick (2009) parte da ideia da transferência da análise de documentos para o âmbito virtual. A estratégia de emprego da coleta on-line dos dados apresentou-se oportuna para a condução da pesquisa dada a condição de disponibilidade e devido ao nível de organização das informações requeridas nos sites consultados.

No que tange à análise, para efeito de sistematização do estudo e a fim de tornar sintético o conjunto das informações, decidiu-se pela organização dos dados em quadros e tabelas. A Tabela 1 , especificamente e citada aqui por tratar-se do núcleo analítico central a esse estudo, foi construída a partir de cálculos de frequência dentro de uma análise univariada.

\section{Análise e Discussão dos Resultados}

Compõem este tópico a apresentação, a análise $e$ a discussão dos resultados. A opção pela inclusão, nas contagens, de componentes curriculares voltados aos temas de gestão social, tem a intenção de reforçar a evidência da marginalização que sofrem os temas organizacionais desvinculados da natureza do mercado.

O Quadro 2 elenca informações gerais a respeito do formato de cada um dos dez cursos analisados na pesquisa. 


\begin{tabular}{|c|c|c|c|c|c|}
\hline IES & TuRno & $\begin{array}{l}\text { ANO DE VIGÊNCIA DO } \\
\text { CURRÍ́CULO ATUAL }\end{array}$ & $\begin{array}{l}\text { QUANTIDADE } \\
\text { DE DISCIPLINAS } \\
\text { OBRIGATÓRIAS }\end{array}$ & $\begin{array}{c}\text { CARGA HORÁRIA EM } \\
\text { DISCIPLINAS OBRIGATÓRIAS }\end{array}$ & $\begin{array}{c}\text { CRÉditos EM DISCIPLINAS } \\
\text { OBRIGATÓRIAS }\end{array}$ \\
\hline UnB & Diurno & 2011 & 28 & 1710 & 114 \\
\hline UFMG & Diurno & 2011 & 39 & 2190 & 146 \\
\hline UFGRS & Diurno & 2010 & 40 & $* 2490$ & *166 \\
\hline UFBA & Diurno & 2011 & 43 & 2737 & 161 \\
\hline UFRJ & Diurno & 1998 & 40 & 2070 & 138 \\
\hline UFPE & Diurno & $* * 2000$ & 39 & 2340 & 156 \\
\hline USP & Diurno & 2002 & 51 & 2010 & 134 \\
\hline UFLA & Diurno & 2013 & 41 & *2329 & $* 137$ \\
\hline UFPB & Diurno & 2007 & 45 & 2535 & 169 \\
\hline UFRN & Diurno & 2011 & 46 & 2475 & 165 \\
\hline
\end{tabular}

* O cursos da UFRGS e UFLA compatibilizam créditos e carga horária de maneira distintas: 1 crédito = 17 horas;

**A informação coletada refere-se ao ano da renovação da autorização do funcionamento do curso pelo MEC.

Quadro 2: Características gerais dos currículos obrigatórios de cursos presenciais de Administração, no nível de graduação Fonte: Elaborado pelos autores deste artigo

Algumas características são objeto de destaque: a) segundo informações disponíveis nos sites das IES pesquisadas (único meio de coleta de dados empregado) as matrizes curriculares que orientam a formação de bacharéis em Administração na UFRJ, UFPE e USP (Faculdade de Economia e Administração - FEA) estão vigentes há mais de 10 anos; b) o Curso de Graduação da FEA/USP desponta como o que possui o maior número de disciplinas obrigatórias: são 51 disciplinas contra as 28 que compõem o currículo do curso na UnB. A carga horária em disciplinas obrigatórias (2.010 horas, a segunda menor carga horária exigida em componentes obrigatórios), no entanto, revela que a extensão do currículo da USP se traduz na matriz curricular mais compartimentada dentro do conjunto de cursos analisados. Neste caso, a maior parte das disciplinas ofertadas são de dois créditos (15 horas/ aula). Nos demais cursos, observa-se uma distribuição mais homogênea entre o quantitativo de componentes obrigatórios e a carga horária obrigatória total exigida. Destaque, neste aspecto, para o curso da UFPE, cuja matriz curricular fundamental é composta somente por disciplinas de 4 créditos ou 60h/aula; c) uma última discrepância a ser levantada se constitui na diferença de mais de 1.000 horas (em disciplinas obrigatórias) que separa a formação do Bacharel em Administração da UFBA (2.737 horas) da formação do Bacharel em Administração da UnB (1.710 horas).
Em parte anterior deste artigo comentou-se acerca do processo de extinção das habilitações com o advento da Resolução n 04/2005/CNE/CSE/MEC. Todos os cursos analisados respeitam esta diretriz $e$ chancelam o grau de Bacharel em Administração aos seus egressos. O curso da UFRJ, no entanto, é operado sob uma dinâmica diferente do processo comum aos demais casos analisados. No cumprimento das cargas horárias eletiva, optativa e complementar o aluno poderá optar por enfatizar a sua formação nas áreas de Administração Internacional, Estratégia Empresarial, Finanças e Controle, Logística, Marketing ou Recursos Humanos.

A existência - no âmbito das IES amostradas de cursos de graduação, presenciais, com dedicação específica na área da Administração Pública e em áreas correlatas é abordada no Quadro 3.

\begin{tabular}{|c|c|c|}
\hline IES & $\begin{array}{c}\text { Possui cursos de } \\
\text { GRAduAÇão ESPECíficos ou } \\
\text { CORRELATOS NAS ÁREAS DE } \\
\text { AdM. PúblicA OU GESTÃo } \\
\text { Social? }\end{array}$ & $\begin{array}{c}\text { CuRSOS ESPECífICOS } \\
\text { OU CORRELATOS }\end{array}$ \\
\hline UnB & Sim & $\begin{array}{c}\text { Gestão de Políticas } \\
\text { Públicas; }\end{array}$ \\
\hline UFMG & Sim & Gestão Pública; \\
\hline UFRGS & Sim & Políticas Públicas; \\
\hline
\end{tabular}




\begin{tabular}{|c|c|c|}
\hline UFBA & Sim & $\begin{array}{l}\text { Tecnologia em } \\
\text { Gestão Pública e } \\
\text { Gestão Social; }\end{array}$ \\
\hline UFRJ & Sim & $\begin{array}{l}\text { Gestão Pública para } \\
\text { o Desenvolvimento } \\
\text { Econômico Social; }\end{array}$ \\
\hline UFPE & Não & - \\
\hline USP & Sim & $\begin{array}{c}\text { Gestão de Políticas } \\
\text { Públicas; }\end{array}$ \\
\hline UFLA & Sim & Administração Pública; \\
\hline UFPB & Não & - \\
\hline UFRN & Sim & $\begin{array}{c}\text { Gestão de Políticas } \\
\text { Públicas; } \\
\text { *Tecnologia em Gestão } \\
\text { de Cooperativas; }\end{array}$ \\
\hline
\end{tabular}

*Este curso não tem oferta regular na UFRN.

Quadro 3: Cursos presenciais de Graduação em temáticas específicas ou correlatas da Administração Pública e da Gestão Social

Fonte: Elaborado pelos autores deste artigo

Esta verificação foi apontada no sentido de investigar se a coexistência de cursos de graduação em Administração (com viés generalista) com Cursos de Graduação na área de Administração Pública produz algum efeito no dimensionamento da carga horária obrigatória voltada às questões das organizações e setor públicos em cursos mais abrangentes. Dito de outro modo, a questão a saber é: os cursos de administração (com vocação generalista) em IES nas quais existe a oferta de cursos dedicados ao campo da administração pública e/ou gestão social tendem a se voltar mais para o campo do mercado? Essa discussão será retomada junto à análise dos dados dispostos na Tabela 1.

Duas únicas IES dentre as elencadas não possuem curso algum de graduação em administração pública ou correlatos na modalidade presencial, são os casos da UFPE e da UFPB. No caso das demais universidades o que se observa é a variedade nas nomenclaturas atribuídas aos cursos: Administração pública, Gestão Pública, Políticas Públicas, Gestão de Políticas Públicas etc.

Outro aspecto a ser levantado no que toca ao limitado espaço que os temas da administração pública ocupam em cursos de graduação em gestão os quais, por força, legal deveriam ampliar o escopo da discussão da atuação do administrador sob a plataforma da pluralidade de organizações, refere-se à dimensão que assumem esses conteúdos em nível de pós-graduação e ao volume de radiação que a presença do campo de públicas em programas de mestrado e doutorado em administração exerce em relação às diretrizes de formação dos bacharéis administradores. No Quadro 4 são listadas evidências da presença (ou ausência) de conteúdos próprios da administração pública ou gestão social nos âmbitos dos programas de pós-graduação em administração vinculados às instituições imbrincados neste estudo.

\begin{tabular}{|c|c|c|c|c|c|}
\hline IES & $\begin{array}{c}\text { Programa de } \\
\text { Pós-Graduação } \\
\text { EM Administração } \\
\text { (ANO) }\end{array}$ & $\begin{array}{c}\text { ÁrEA(s) DE } \\
\text { CoNCENTRAÇÃo } \\
\text { VINCULADAS À AP } \\
\text { OU GS }\end{array}$ & $\begin{array}{c}\text { Linha(s) DE } \\
\text { Pesquisa EM AP } \\
\text { ou GS }\end{array}$ & $\begin{array}{c}\text { Mestrado } \\
\text { Profissional (MP) } \\
\text { EM AP ou GS }\end{array}$ & $\begin{array}{c}\text { Núcleo(s)/Grupo(s) De Pesquisa } \\
\text { E/ou Estudos Em AP ou GS }\end{array}$ \\
\hline UnB & PPGA (1976) & $\begin{array}{c}\text { Administração } \\
\text { Pública e Políticas } \\
\text { Públicas }\end{array}$ & - & $\begin{array}{l}\text { MP em Administração } \\
\text { Pública }\end{array}$ & - \\
\hline UFMG & CEPAD (1972) & - & $\begin{array}{l}\text { 1. Estudos sobre } \\
\text { Gestão Pública; } \\
\text { 2. Gestão e } \\
\text { Finanças Públicas }\end{array}$ & - & $\begin{array}{l}\text { Núcleo de Estudos sobre } \\
\text { Gestão Pública }\end{array}$ \\
\hline UFRGS & PPGA (1972) & - & - & - & $\begin{array}{l}\text { 1. Núcleo de Estudos e Tecnologias } \\
\text { em Gestão Pública; 2. Núcleo } \\
\text { Interdisciplinar de Pesquisa e Estudos } \\
\text { sobre o Terceiro Setor; 3. Grupo } \\
\text { de Pesquisa "Estado, Democracia } \\
\text { e Administração Pública" }\end{array}$ \\
\hline
\end{tabular}




\begin{tabular}{|c|c|c|c|c|c|}
\hline UFBA & NPGA (1983) & $\begin{array}{l}\text { Administração } \\
\text { Pública e } \\
\text { Governança }\end{array}$ & $\begin{array}{l}\text { Gestão de } \\
\text { Instituições, } \\
\text { Finanças e } \\
\text { Políticas Públicas }\end{array}$ & $\begin{array}{c}\text { Mestrado } \\
\text { Multidisciplinar e } \\
\text { Profissionalizante em } \\
\text { Desenvolvimento } \\
\text { e Gestão Social }\end{array}$ & $\begin{array}{l}\text { 1. Centro Interdisciplinar de } \\
\text { Desenvolvimento e Gestão } \\
\text { Social; } 2 \text {. Núcleo de Instituições, } \\
\text { Finanças e Políticas Públicas }\end{array}$ \\
\hline UFRJ & COPPEAD (1973) & - & - & - & - \\
\hline UFPE & $\begin{array}{l}\text { PROPAD (1995) } \\
\text { MPG (2001) }\end{array}$ & - & - & $\begin{array}{l}\text { MP em Gestão } \\
\text { Pública para o } \\
\text { Desenvolvimento } \\
\text { do Nordeste }\end{array}$ & $\begin{array}{l}\text { 1. Grupo Interdisciplinar } \\
\text { de Pesquisas e Estudos em } \\
\text { Sustentabilidades; } 2 \text {. Núcleo } \\
\text { Interdisciplinar de Estudos } \\
\text { sobre Capital Social }\end{array}$ \\
\hline USP & PPGA (1972) & - & $\begin{array}{l}\text { Responsabilidade } \\
\text { Socioambiental }\end{array}$ & - & $\begin{array}{l}\text { Centro de Empreendedorismo Social } \\
\text { e Administração em Terceiro Setor }\end{array}$ \\
\hline UFLA & PPGA (1975) & - & $\begin{array}{l}\text { Gestão e Políticas } \\
\text { Públicas }\end{array}$ & $\begin{array}{l}\text { MP em } \\
\text { Desenvolvimento } \\
\text { Sustentável e } \\
\text { Extensão }\end{array}$ & $\begin{array}{l}\text { Núcleo de Estudos e } \\
\text { Pesquisas em Administração } \\
\text { Pública e Gestão Social }\end{array}$ \\
\hline UFPB & PPGA (1976) & - & - & - & $\begin{array}{c}\text { Núcleo de Estudos sobre Estado, } \\
\text { Trabalho e Sociedade }\end{array}$ \\
\hline UFRN & $\begin{array}{l}\text { PPGA (1978) } \\
\text { PPGP (2010) }\end{array}$ & $\begin{array}{l}\text { Política e Gestão } \\
\text { Públicas }\end{array}$ & $\begin{array}{l}\text { Políticas Públicas } \\
\text { e Governança }\end{array}$ & MP em Gestão Pública & $\begin{array}{c}\text { Base de Pesquisa Gestão } \\
\text { Institucional e Políticas Públicas }\end{array}$ \\
\hline
\end{tabular}

Quadro 4: Evidências da presença de temas do campo de públicas em programas de pós-graduação em administração Fonte: Elaborado pelos autores deste artigo

A partir do Quadro 4 é possível observar que, de forma quase absoluta (a exceção é o caso da COPPE$\mathrm{AD} / \mathrm{UFRJ})$, em maior ou menor medida, conteúdos de administração pública ou de gestão social podem ser encontrados nos programas de pós-graduação em administração das instituições pesquisadas. Dois casos significativos a serem destacados são os da UFBA e o da UFRN. Nessas duas instituições foi possível identificar um conjunto de estruturas e diretrizes, nas áreas do ensino e da pesquisa em administração, que privilegiam o campo de públicas. Ambas as instituições contam no nível interno de seus programas de pós-graduação com áreas de concentração e linhas de pesquisa dedicadas, de forma exclusiva, a debate de conteúdos de interesse das organizações públicas (estatais e não estatais). Também nestas IES foram identificadas núcleos de estudos e pesquisa com foco nos temas da administração pública.

$\mathrm{O}$ passo seguinte às análises das informações gerais dos cursos e à verificação da existência de graduações específicas na área de administração pública no âmbito das universidades pesquisadas foi analisar a composição dos currículos dos dez cursos imbrincados no estudo: os cursos de graduação em administração, bacharelados, da Universidade de Brasília (UnB), Universidade Federal de Minas Gerais (UFMG), Universidade Federal do Rio Grande do Sul (UFRGS), Universidade Federal da Bahia (UFBA), Universidade Federal do Rio de Janeiro (UFRJ), Universidade Federal de Pernambuco (UFPE), Universidade de São Paulo (USP), Universidade Federal de Lavras (UFLA), Universidade Federal da Paraíba (UFPB) e Universidade Federal do Rio Grande do Norte (UFRN).

Para fins de caracterização de componentes curriculares obrigatórios como sendo pertencentes ao rol das disciplinas de administração pública estabeleceu-se como requisito a identificação textual, no título dos componentes, dos seguintes designativos: políticas públicas, administração pública, governo, Estado, gestão social, organizações não-governamentais e empreendimentos solidários. Os componentes curriculares que satisfizeram a, pelo menos, um desses requisitos, pinçados nas matrizes curriculares obrigatórias dos cursos de graduação em Administração, foram relacionados no Quadro 5. 


\begin{tabular}{|c|c|c|}
\hline IES & $\begin{array}{c}\text { Disciplinas DE } \\
\text { AdMINISTRAÇÃo PúBlica }\end{array}$ & $\begin{array}{c}\text { DisciplinAs dE GESTÃo } \\
\text { SOCIAL }\end{array}$ \\
\hline UnB & $\begin{array}{l}\text { 1. Fundamentos da } \\
\text { Administração Pública; }\end{array}$ & - \\
\hline UFMG & - & - \\
\hline UFRGS & $\begin{array}{c}\text { 1. Oficina II: } \\
\text { Administração e } \\
\text { Governo no Brasil; }\end{array}$ & $\begin{array}{l}\text { 1. Oficina IV: } \\
\text { Gestão Social e } \\
\text { Desenvolvimento; }\end{array}$ \\
\hline UFBA & $\begin{array}{l}\text { 1. Estado e Sociedade; } \\
\text { 2. Políticas Públicas e } \\
\text { Gestão Governamental; } \\
\text { 3. Orçamento e } \\
\text { Finanças Públicas; } \\
\text { 4. Administração Política }\end{array}$ & - \\
\hline UFRJ & - & - \\
\hline UFPE & $\begin{array}{l}\text { 1. Administração Pública; } \\
\text { 2. Administração de } \\
\text { Políticas Públicas; }\end{array}$ & - \\
\hline USP & - & - \\
\hline UFLA & - & - \\
\hline UFPB & - & - \\
\hline UFRN & $\begin{array}{l}\text { Fundamentos da } \\
\text { Administração Pública; } \\
\text { 2. Poder, Política } \\
\text { e Gestão; } \\
\text { 3. Planejamento } \\
\text { Governamental; } \\
\text { 4. Orçamento Público; } \\
\text { 5. Novas tecnologias } \\
\text { na Gestão Pública. }\end{array}$ & $\begin{array}{l}\text { 1. Gestão de } \\
\text { Empreendimentos } \\
\text { Não-Governamentais; } \\
\text { 2. Gestão de } \\
\text { Empreendimentos } \\
\text { Econômico Solidários; }\end{array}$ \\
\hline
\end{tabular}

Quadro 5: Disciplinas de Administração Pública identificadas nos currículos analisados

Fonte: Elaborado pelos autores deste artigo

A disciplina "Administração Política", pertencente ao currículo do curso da UFBA, e a disciplina "Poder, Política e Gestão", do currículo da UFRN foram incluídas após confirmação da compatibilidade entres conteúdos disciplinar e temas da administração pública. Esta confirmação se deu via acesso às ementas dos componentes. Ainda a respeito das informações incluídas no Quadro 5, percebe-se que cada currículo lança mão de uma abordagem particular sobre o tema da administração pública e em só caso pode-se verificar a reincidência em nomenclaturas de componentes: Fundamentos da Administração Pública, nas matrizes da UnB e da UFRN.

No Quadro 6 estão dispostas, de forma cruzada, as informações já apresentadas nos Quadros 2 e 3. Esses dados foram confrontados no sentido de viabilizar inferência a respeito da relação entre a existência de cursos dedicados ao campo da administração pública e/ou gestão social e o esvaziamento curricular de componentes obrigatórios específicos deste campo em cursos de vocação generalista:

\begin{tabular}{|c|c|c|c|}
\hline IES & $\begin{array}{c}\text { O curso } \\
\text { generalista } \\
\text { possui } \\
\text { disciplinas de } \\
\text { Administração } \\
\text { Pública/Gestão } \\
\text { Social? }\end{array}$ & $\begin{array}{c}\text { Possui } \\
\text { graduação } \\
\text { específica? }\end{array}$ & $\begin{array}{c}\text { Resultado } \\
\text { da } \\
\text { verificação }\end{array}$ \\
\hline UnB & $\operatorname{Sim}(1)$ & Sim & Negativo \\
\hline UFMG & Não & Sim & Positivo \\
\hline UFRGS & Sim (1) & Sim & Negativo \\
\hline UFBA & $\operatorname{Sim}(4)$ & Sim & Negativo \\
\hline UFRJ & Não & Sim & Positivo \\
\hline UFPE & Sim (2) & Não & Positivo \\
\hline USP & Não & Sim & Positivo \\
\hline UFLA & Não & Sim & Positivo \\
\hline UFPB & Não & Não & Negativo \\
\hline UFRN & Sim (7) & Sim & Negativo \\
\hline
\end{tabular}

Quadro 6: Coexistência de cursos específicos e componentes de Administração Pública e/ou Gestão Social em cursos generalistas

Fonte: Elaborado pelos autores deste artigo

A hipótese de partida é a de que a inexistência de cursos específicos da área de administração pública ou gestão social refletiria na presença de componentes curriculares específicos do campo de públicas em cursos de administração com natureza generalista. Nessa perspectiva, o conjunto das informações captadas e arroladas neste estudo permitem concluir que não existe relação entre estas duas condicionantes. Metade dos casos confirmou a hipótese e metade a negou. Na UFPE, por exemplo, a hipótese foi confirmada: o curso de administração com vocação generalista inclui no seu rol de componentes obrigatórios duas disciplinas do campo de públicas, ao passo em que não existe um curso específico onde estes temas pudessem ser tratados de forma dedicada. Já no caso da UFRN, apesar da existência de dois cursos específicos vinculados ao universo da administração pública, na graduação em administração estão dispostas sete disciplinas com raiz no campo de públicas. 
O resultado do exercício de quantificação das disciplinas na área de Administração Pública está apresentado na Tabela 1. A distribuição inicial dos itens curriculares a partir das classes "formação básica", "formação profissional" e "estudos quantitativos" diz respeito à taxonomia estabelecida na Resolução n· 04/2005/CNE/CSE/ MEC para a identificação da natureza das disciplinas na composição das matrizes curriculares. Esses campos de formação, conforme artigo $5^{\circ}$ das Diretrizes Curriculares Nacionais para Cursos de Graduação, Bacharelado, em Administração, caracterizam-se em

I) Conteúdos de Formação Básica: relacionados com estudos antropológicos, sociológicos, filosóficos, psicológicos, ético-profissionais, políticos, comportamentais, econômicos e contábeis, bem como os relacionados com as tecnologias da comunicação e da informação e das ciências jurídicas;

II) Conteúdos de Formação Profissional: relacionados com as áreas específicas, envolvendo teorias da administração e das organizações e a administração de recursos humanos, mercado e marketing, materiais, produção e logística, financeira e orçamentária, sistemas de informações, planejamento estratégico e serviços;

III.Conteúdos de Estudos Quantitativos e suas Tecnologias: abrangendo pesquisa operacional, teoria dos jogos, modelos matemáticos e estatísticos e aplicação de tecnologias que contribuam para a definição e utilização de estratégias e procedimentos inerentes à administração;

Quanto à composição dos currículos obrigatórios, tomando-se como ponto de partida a proporção que representa cada um dos três tipos de componentes, verifica-se uma tênue tendência distributiva. Seis IES (UnB, UFMG, UFRGS, UFBA, UFRJ e USP) dimensionam os currículos obrigatórios (sendo a unidade analítica "créditos obrigatórios") em: aproximadamente de 30\% a 35\% em conteúdos de 'formação básica' e; aproximadamente de $50 \%$ a $60 \%$ em conteúdos de "formação profissional". A proporção de créditos obrigatórios em conteúdos de estudos quantitativos, nos currículos da UnB, UFMG e UFRJ é praticamente equânime: na casa dos $17 \%$. Os currículos que apresentam maior diferença, quanto à formatação, em relação aos demais, é o currículo do Curso de Administração da UFPE. Neste, 71,79\% da carga horária obrigatória são destinados aos conteúdos de formação profissional. O Curso de Administração da UFMG, com 26 créditos em 7 componentes, mostrou-se como sendo o mais quantitativista. Em média, excluindo-se o caso atípico do currículo da UFPE, $15 \%$ da carga horária obrigatória nos cursos analisados são destinados à formação em métodos quantitativos.

Tabela 1: Dimensionamento de disciplinas de Adm. Pública e de Gestão Social em currículos obrigatórios de cursos de Administração (graduação)

\begin{tabular}{|c|c|c|c|c|c|}
\hline & IES & Formação Básıca & $\begin{array}{c}\text { Formação } \\
\text { Profissional }\end{array}$ & $\begin{array}{c}\text { Estudos } \\
\text { Quantitativos }\end{array}$ & TOTAIS \\
\hline \multirow{10}{*}{ Disciplinas Obrigatórias } & UnB & $10 / 35,71 \%$ & $14 / 50 \%$ & $4 / 14,29 \%$ & $28 / 100 \%$ \\
\hline & UFMG & $12 / 30,77 \%$ & $20 / 51,28 \%$ & $7 / 17,95 \%$ & $39 / 100 \%$ \\
\hline & UFRGS & $14 / 35 \%$ & $21 / 52,50 \%$ & $5 / 12,50 \%$ & $40 / 100 \%$ \\
\hline & UFBA & $12 / 27,91 \%$ & $26 / 60,47 \%$ & $5 / 11,63 \%$ & $43 / 100 \%$ \\
\hline & UFRJ & $15 / 37,50 \%$ & $19 / 47,50 \%$ & $6 / 15 \%$ & $40 / 100 \%$ \\
\hline & UFPE & $9 / 23,08 \%$ & $28 / 71,79 \%$ & $2 / 5,13 \%$ & $39 / 100 \%$ \\
\hline & USP & $13 / 25,49 \%$ & $33 / 64,71 \%$ & $5 / 9,80 \%$ & $51 / 100 \%$ \\
\hline & UFLA & 12 / 29,27\% & $24 / 58,54 \%$ & $5 / 12,20 \%$ & $41 / 100 \%$ \\
\hline & UFPB & $11 / 24,44 \%$ & $29 / 64,44 \%$ & $5 / 11,11 \%$ & $45 / 100 \%$ \\
\hline & UFRN & $9 / 19,57 \%$ & $33 / 71,74 \%$ & $4 / 8,70 \%$ & $46 / 100 \%$ \\
\hline \multirow{10}{*}{ Créditos Obrigatórios } & UnB & $36 / 31,58 \%$ & $58 / 50,88 \%$ & $20 / 17,54 \%$ & $114 / 100 \%$ \\
\hline & UFMG & 44 / 30,14\% & $76 / 52,05 \%$ & $26 / 17,81 \%$ & $146 / 100 \%$ \\
\hline & UFRGS & $56 / 33,73 \%$ & $88 / 53,01 \%$ & $22 / 13,25 \%$ & $166 / 100 \%$ \\
\hline & UFBA & 47 / 29,19\% & 93 / 57,76\% & $21 / 13,04 \%$ & $161 / 100 \%$ \\
\hline & UFRJ & $50 / 36,23 \%$ & 64 / 46,38\% & $24 / 17,39 \%$ & $138 / 100 \%$ \\
\hline & UFPE & $36 / 23,08 \%$ & 112 / 71,79\% & $8 / 5,13 \%$ & $156 / 100 \%$ \\
\hline & USP & 40 / 29,85\% & 80 / 59,70\% & $14 / 10,45 \%$ & $134 / 100 \%$ \\
\hline & UFLA & 39 / 28,47\% & 80 / 58,39\% & $18 / 13,14 \%$ & 137 / 100\% \\
\hline & UFPB & 44 / 26,04\% & $105 / 62,13 \%$ & 20 / 11,83\% & $169 / 100 \%$ \\
\hline & UFRN & 35 / 21,21\% & $116 / 70,30 \%$ & 14 / 8,48\% & $165 / 100 \%$ \\
\hline
\end{tabular}




\begin{tabular}{|c|c|c|c|c|c|}
\hline & IES & FoRMAÇÃo Básica & $\begin{array}{c}\text { Formação } \\
\text { Profissional }\end{array}$ & $\begin{array}{c}\text { Estudos } \\
\text { Quantitativos }\end{array}$ & TOTAIS \\
\hline \multirow{10}{*}{$\begin{array}{l}\text { Disciplinas Obrigatórias } \\
\text { de Adm. Pública }\end{array}$} & UnB & $0 / 0 \%$ & $1 / 7,14 \%$ & $0 / 0 \%$ & $1 / * 3,57 \%$ \\
\hline & UFMG & $0 / 0 \%$ & $0 / 0 \%$ & $0 / 0 \%$ & NA \\
\hline & UFRGS & $0 / 0 \%$ & $1 / 4,76 \%$ & $0 / 0 \%$ & $1 / * 2,50 \%$ \\
\hline & UFBA & $1 / 8,33 \%$ & $3 / 11,54 \%$ & $0 / 0 \%$ & $4 / * 9,30 \%$ \\
\hline & UFRJ & $0 / 0 \%$ & $0 / 0 \%$ & $0 / 0 \%$ & NA \\
\hline & UFPE & $0 / 0 \%$ & $2 / 7,14 \%$ & $0 / 0 \%$ & $2 / * 5,13 \%$ \\
\hline & USP & $0 / 0 \%$ & $0 / 0 \%$ & $0 / 0 \%$ & NA \\
\hline & UFLA & $0 / 0 \%$ & $0 / 0 \%$ & $0 / 0 \%$ & NA \\
\hline & UFPB & $0 / 0 \%$ & $0 / 0 \%$ & $0 / 0 \%$ & NA \\
\hline & UFRN & $0 / 0 \%$ & $5 / 15,15 \%$ & $0 / 0 \%$ & $5 / 10,87 \%$ \\
\hline \multirow{10}{*}{$\begin{array}{l}\text { Créditos Obrigatórios } \\
\text { Disciplina de } \\
\text { Administração Pública }\end{array}$} & UnB & $0 / 0 \%$ & $4 / 6,90 \%$ & $0 / 0 \%$ & $4 / * 3,51 \%$ \\
\hline & UFMG & $0 / 0 \%$ & $0 / 0 \%$ & $0 / 0 \%$ & NA \\
\hline & UFRGS & $0 / 0 \%$ & $6 / 6,82 \%$ & $0 / 0 \%$ & $6 / * 3,61 \%$ \\
\hline & UFBA & $4 / 8,51 \%$ & $11 / 11,83 \%$ & $0 / 0 \%$ & $15 / * 9,32 \%$ \\
\hline & UFRJ & $0 / 0 \%$ & $0 / 0 \%$ & $0 / 0 \%$ & NA \\
\hline & UFPE & $0 / 0 \%$ & $8 / 7,14 \%$ & $0 / 0 \%$ & $8 / * 5,13 \%$ \\
\hline & USP & $0 / 0 \%$ & $0 / 0 \%$ & $0 / 0 \%$ & NA \\
\hline & UFLA & $0 / 0 \%$ & $0 / 0 \%$ & $0 / 0 \%$ & NA \\
\hline & UFPB & $0 / 0 \%$ & $0 / 0 \%$ & $0 / 0 \%$ & NA \\
\hline & UFRN & $0 / 0 \%$ & $16 / 13,79 \%$ & $0 / 0 \%$ & $16 / 9,70 \%$ \\
\hline \multirow{10}{*}{$\begin{array}{l}\text { Disciplinas Obrigatórias } \\
\text { de Gestão Social }\end{array}$} & UnB & $0 / 0 \%$ & $0 / 0 \%$ & $0 / 0 \%$ & NA \\
\hline & UFMG & $0 / 0 \%$ & $0 / 0 \%$ & $0 / 0 \%$ & NA \\
\hline & UFRGS & $0 / 0 \%$ & $1 / 4,76 \%$ & $0 / 0 \%$ & $1 / * 2,5 \%$ \\
\hline & UFBA & $0 / 0 \%$ & $0 / 0 \%$ & $0 / 0 \%$ & NA \\
\hline & UFRJ & $0 / 0 \%$ & $0 / 0 \%$ & $0 / 0 \%$ & NA \\
\hline & UFPE & $0 / 0 \%$ & $0 / 0 \%$ & $0 / 0 \%$ & NA \\
\hline & USP & $0 / 0 \%$ & $0 / 0 \%$ & $0 / 0 \%$ & NA \\
\hline & UFLA & $0 / 0 \%$ & $0 / 0 \%$ & $0 / 0 \%$ & NA \\
\hline & UFPB & $0 / 0 \%$ & $0 / 0 \%$ & $0 / 0 \%$ & NA \\
\hline & UFRN & $0 / 0 \%$ & $2 / 6,06 \%$ & $0 / 0 \%$ & $2 / 4,35 \%$ \\
\hline \multirow{10}{*}{$\begin{array}{l}\text { Créditos Obrigatórios } \\
\text { Disciplina Gestão Social }\end{array}$} & UnB & $0 / 0 \%$ & $0 / 0 \%$ & $0 / 0 \%$ & NA \\
\hline & UFMG & $0 / 0 \%$ & $0 / 0 \%$ & $0 / 0 \%$ & NA \\
\hline & UFRGS & $0 / 0 \%$ & $4 / 4,54 \%$ & $0 / 0 \%$ & $4 / * 2,41$ \\
\hline & UFBA & $0 / 0 \%$ & $0 / 0 \%$ & $0 / 0 \%$ & NA \\
\hline & UFRJ & $0 / 0 \%$ & $0 / 0 \%$ & $0 / 0 \%$ & NA \\
\hline & UFPE & $0 / 0 \%$ & $0 / 0 \%$ & $0 / 0 \%$ & NA \\
\hline & USP & $0 / 0 \%$ & $0 / 0 \%$ & $0 / 0 \%$ & NA \\
\hline & UFLA & $0 / 0 \%$ & $0 / 0 \%$ & $0 / 0 \%$ & NA \\
\hline & UFPB & $0 / 0 \%$ & $0 / 0 \%$ & $0 / 0 \%$ & NA \\
\hline & UFRN & $0 / 0 \%$ & $4 / 3,45 \%$ & $0 / 0 \%$ & $4 / 2,42 \%$ \\
\hline
\end{tabular}

*Este percentual refere-se ao total de créditos obrigatórios, de uma forma geral.

Fonte: Dados da pesquisa

Atestando a condição marginal que os temas relacionados à Administração Pública e Gestão Social ocupam nos currículos de Cursos de Graduação em Administração generalistas, tem-se que: a) nos cursos da UFMG, da UFRJ, da USP, da UFLA e da UFPE inexistem componentes curriculares dedicados às questões atinentes à disciplina da Administração Pública ou Gestão Social; b) os cursos que dimensionam maior proporção em carga horária obrigatória entre componentes de Administração Pública (AP) ou Gestão Social (GS) são os da UFBA $(9,32 \%$, créditos em disciplinas de AP) e o da UFRN (12,12\%, sendo 9,70\% em AP e 2,42\% \% em GS). Nestes cursos, observa-se, a formação dos alunos é voltada ao conhecimento em organizações pautadas sob outros campos epistemológicos, afora o de mercado.

Em terceiro lugar, na disposição de conteúdos de Administração e/ou Gestão Social nos currículos, está o 
curso da UFRGS, com 3,61\% dos créditos obrigatórios na disciplina 'Oficina II: Administração e Governo no Brasil' e 2,41\% dos créditos obrigatórios na disciplina 'Oficina IV: Gestão Social e Desenvolvimento'. Somados estes créditos, tem-se que $6,02 \%$ do currículo do Curso de Graduação em Administração da UFRGS foge ao domínio do viés mercadológico. O Curso de Administração da UFPE dedica $7,14 \%$ da carga horária em conteúdos de formação profissional do seu currículo aos temas da "Administração Pública" e da "Administração de Políticas Públicas".

\section{Conclusões}

Em linhas gerais, o que está posto corrobora com a hipótese de que a disciplina da Administração Pública é pouco explorada em processos generalistas de ensino-aprendizagem em administração em nível de graduação. Essa evidência foi construída tendo sido analisados os currículos de Cursos de Administração em IES com reconhecida contribuição no desenvolvimento deste campo do conhecimento, a partir do valor atribuído aos seus Programas de Pós-Graduação em Administração.

Outra conclusão que se alcança a partir dessa investigação diz respeito à reduzida correspondência existente entre os programas formativos em nível de pós-graduação em administração, a abertura que estes já têm dado para a discussão de questões próprias do campo de públicas e os currículos dos cursos de graduação em administração ofertados dentro do mesmo contexto institucional.

No que se refere à busca por algum efeito no dimensionamento do volume de conteúdos da área pública em estruturas curriculares submetidas ao conjunto mais abrangente das DCNs (Resolução n. 4/2005/ $\mathrm{CNE}$ ) em IES nas quais coexistem cursos dedicados ao ensino de Administração Pública a pesquisa respondeu não existirem evidências de alguma relação neste sentido. Infere-se disso, que o surgimento de cursos do campo de públicas, nas IES arroladas neste estudo, não implicou em mudanças no tratamento que programas de formação mais abrangentes empregaram aos temas da administração pública.

A partir da análise dos casos da Universidade Federal da Bahia e da Universidade Federal do Rio Grande, em que se encontram arranjos institucionais vocacionados ao debate organizacional na esfera pública, pode-se inferir a existência de uma relação positiva entre a presença significativa de componentes curriculares específicos da área pública ou social, em cursos de Administração "não específicos", e programas de pós-graduação com tradição na construção da pesquisa em Administração Pública ou em Gestão Social. Nessas instituições, verificou-se correspondência entre a tradição de seus programas de pós-graduação $e$ a inserção de disciplinas voltadas à compreensão da influência da esfera pública no contexto organizacional.

A Administração Pública e a Gestão Social, no contexto dos cursos envolvidos nesta pesquisa, ocupam limitado espaço no processo de ensino-aprendizagem que vivenciam os alunos de graduação. Em detrimento dessa abordagem "plural" e "democrática" acerca do universo organizacional, aos administradores formados pela maior parte dessas IES é apresentada uma única face da complexidade que envolve o fazer administrativo, sendo-lhes ocultada a possibilidade de compreender o ambiente organizacional a partir da sua relação com o mundo, a despeito do "mercadocentrismo" em que insere parcela da sociedade ocidentalizada.

A título de consideração conclusiva em defesa da manutenção de estruturas curriculares transitivas no que se refere à presença de conteúdos de Administração Pública e Gestão Social em cursos à guisa das DCNs inespecíficas, cumpre aludir que o Estado, o mercado e a sociedade integram um conjunto complexo de dimensões indissociáveis. Corroborando esta perspectiva, Bresser-Pereira (2009, p. 1) explica que

O Estado é o sistema constitucional-legal e a organização que o garante; é, portanto, a instituição fundamental de cada sociedade, é a matriz das demais instituições, é o princípio coordenador ou regulador com poder sobre toda a sociedade e o aparelho político que permanentemente o executa e reforma. É por meio da lei ou da ordem jurídica que se coordenam as ações sociais, e é por meio da administração pública que se garante essa coordenação. Já o mercado é uma instituição mais limitada, mas igualmente fundamental: é o mecanismo de competição econômica regulado pelo Estado que logra uma coordenação relativamente automática das ações econômicas; é a instituição que complementa a coordenação mais ampla realizada pelo Estado. Não faz sentido, portanto, opor Estado a mercado. 
Portanto, a tarefa de formar administradores capazes de produzir resultados positivos, seja em organizações privadas, públicas ou sociais, requer que se proporcionem, no decurso dos processos educacionais, experiências de imersão em ambientes organizacionais com raízes distintas, bem como estratégias de ensino que valorizem a intersetorialidade e a transacionalidade do mundo organizacional.

\section{REFERÊNCIAS}

ANDION, Carolina. Gestão em organizações da economia solidária: contornos de uma problemática. Revista de Administração Pública, [S.l.], v. 32, n. 1, p. 7-25, 1998.

\section{AKTOUF, O. Pós-globalização, administração e} racionalidade econômica: a síndrome do avestruz. São Paulo: Atlas, 2004.

Ensino de administração: por uma pedagogia da mudança. Revista de Administração de Empresas, [S.l.], v. 12, n. 35, out.-dez. p. 151-160, 2005.

BERTERO, C. O. Ensino e pesquisa em administração. São Paulo: Thomson Learning, 2006.

BRESSER-PEREIRA, Luiz Carlos. Assalto ao Estado e ao mercado, neoliberalismo e teoria econômica. Revista

Estudos Avançados, [S.I.], v. 23, n. 66, p. 7-22, 2009.

\section{CANÇADO, A. C. Fundamentos teóricos da gestão} social. 2011. 246 p. Tese (Doutorado em Administração) - Universidade Federal de Lavras, Lavras, 2011.

CANÇADO, Airton Cardoso; PEREIRA, José Roberto; TENÓRIO, Fernando Guilherme. Gestão social: epistemologia de um paradigma. Curitiba: CRV, 2013. $216 \mathrm{p}$.

CAPES. Coordenação de Aperfeiçoamento de Pessoal de Nível Superior. Cursos recomendados e reconhecidos. [2013]. Disponível em: < www.capes.gov.br/avaliacao/ cursos-recomendados-e-reconhecidos > . Acesso em: 30 jul. 2013.

\section{CHEVALLIER, J.; LORSCHAK, D. A ciência}

administrativa. Lisboa: Publicações Europa-América, 1980.
COELHO, Fernando S. A problemática atual do ensino de graduação em administração pública no Brasil. Cadernos EBAPE BR, [S.l.], número especial, p. 1-21, ago. 2008.

COELHO, F. S., NICOLINI, A. M. Do auge à retração: análise de um dos estágios de Construção do Ensino de Administração Pública no Brasil (1966- 82).

Organizações \& Sociedade, Salvador, v. 20, n. 66, p. 403-422, jul.-set., 2013.

FADUL, Élvia; MAC-ALLISTER DA SILVA, Mônica

A. Limites e possibilidades de abordagens inter, multi $e$ transdisciplinares para as áreas temáticas de administração pública e gestão social e estudos organizacionais. Revista de Administração

Contemporânea, [S.I.], v. 13, n. 3, p. 351-365, jul.-ago. 2009.

FISCHER, T. O ensino de Administração Pública no

Brasil: os ideais de desenvolvimento e as dimensóes de racionalidade (1948-1984). 1984. Tese de (Doutorado) Faculdade de Economia e Administração da Universidade de São Paulo, São Paulo, 1984.

Administração pública como área de conhecimento e ensino: a trajetória brasileira. Revista de Administração de Empresas, [S.I.], out.-dez. 1984.

FRANÇA FILHO, Genauto Carvalho. Gestão Social: Um Conceito em Construção. In: IX COLÓQUIO INTERNACIONAL SOBRE PODER LOCAL - II COLÓQUIO INTERNACIONAL EL ANÁLISIS DE LAS ORGANIZACIONES Y LA GESTIÓN ESTRATÉGICA: PERSPECTIVAS LATINAS. Salvador, Bahia. 16 a 18 de junho de 2003. Anais... Salvador Bahia, 2003. p. 1-6. KUHN, Thomas S. A estrutura das revoluções científicas. São Paulo: Perspectiva, 1978.

LOPES, P. C. A formação do administrador no ensino de graduação: uma reflexão. Semina: Ciências Sociais e Humanas, Londrina, v. 27, n. 2, p. 187-201, jul.-dez. 2006.

MOTTA, F. C. P.; VASCONCELOS, I. F. G. de. Teoria Geral da Administração. São Paulo: Pioneira, 2006.

POLANYI, K. A grande transformação: as origens da nossa época. 4. ed. Rio de Janeiro: Campus, 2000. p. 51-157. 
RAMOS, A. G. A nova ciência das organizações. 2.

ed. Rio de Janeiro: Editora da Fundação Getúlio Vargas, 1989.

SOUZA, W. J.; OLIVEIRA, M. D. Fundamentos da gestão social na revolução industrial: leitura e crítica aos ideais de Robert Owen. O \& S. Organizações \& Sociedade, [S.I.], v. 13, p. 59-76, 2006.

TONET, Helena Correa et al. Qualidade na administração pública. Revista de Administração Pública, [S.l.], v. 28, n. 2, p. 137-152, 1994. 